\title{
The analysis of the measurements of financial stability
}

\author{
Boshi Zhao \\ University of Missouri-Columbia, Missouri 65201, America \\ boss19920920@outlook.com
}

\begin{abstract}
As the worldwide financial crisis happened more and more frequently, the financial policy makers and researchers have realized importance of the measurements of financial stability. Based on the definition and the characteristics of financial stability, this paper analyzes the evaluation indicators and measurements of financial stability. And the development of the measurements of financial stability plays a key role in the world monetary authority's prevention, risk identification and management of the financial system.
\end{abstract}

Keywords: financial stability; financial system; evaluation indicators.

\section{Introduction}

As the main part of modern market economy, the financial system plays a more and more important role in the economic growth of countries. However, the instability of the financial system has been gradually revealed. Especially in the early 21century, a severe financial crisis had been breaking out around the whole world, which made the financial policy maker realized that the stability of financial system is an indispensable important factor in the economic growth. Therefore, keeping the stability of financial system while promoting the economic growth is becoming the significant research question in economic area. With the development of modern computer technology, the measurements of financial stability have been widely developed, and become more and more accurate, which is a big help for the world monetary authorities to prevention, identification and management of the financial system.

\section{The definition and the characteristics of financial stability}

\subsection{The definition of financial stability}

Although it has been developed for half century, the accurate definition of financial stability has not get broad consensus. Researchers mainly define the financial stability from two point of views, the stability and instability.

The Swedish central bank is the first to propose the concept of financial stability, Wellink and Schinasi defined the financial stability from the angle of resists the crisis. From their point of view, When the exogenous fluctuations impact the real economy, the financial system with stability can effectively guide the running of real economy and weaken the impact of the fluctuation to the real economy [1,2]. As the development of the financial stability research, many researchers also define the financial stability from the opposite, to reveal the disadvantages of financial instability to the whole financial system. The financial instability can be defined from the perspective of asset price change, use the massive swings in asset prices as the negative signal of the stability of the financial institution[3].

Although many financial scholars and financial institutions put different interpretations on the financial stability, the definition of financial stability can be summarized as follows: the financial stability is a healthy market condition, market participants have reasonable expectations and the asset prices in financial markets is not in a massive shock, the financial system can fully and effectively play its role in economic system, and can effectively manage the financial risks, promote the employment and the real economy development.

\subsection{The characteristics of financial stability}

According to the analysis of the definition of financial stability, the characteristics of financial stability can be summarized into four points: 
Firstly, the financial stability is a macro-concept, it is the stability of the whole macro-financial system. The central bank has the responsibility of keeping the stability of whole financial market and the stability of other related industries. Secondly, financial stability is a comprehensive concept. A healthy financial system needs a comprehensive effort from all aspects. When the instability of financial system accrues, financial supervision and regulation department need to take a variety of measures, a variety of policies are needed to directly or indirectly affect the financial market and the real economy. Thirdly, financial stability is a dynamic concept, the economic environment changes over time, and from a long-term point of view, a financial system is needed to systematic prevent, identify and avoid the financial risk and maintain the financial stability. Fourthly, the concept of financial stability contains the meaning of benefits. A stable financial system can make the social resources achieve a more optimized configuration and make the opportunity to gain economic benefits greatly ascend.

\section{The evaluation indicators of financial stability}

The financial crisis happened during the 21century gave serious influence on the national economic development in the world. Therefore, international financial institutions and countries began to rethink the constitute of their financial system, the capacity of crisis resist and their supervision mechanism. Many countries began to build their own indicators of financial stability to ensure the normal operation of the financial systems. Specifically, the indicators which is more mature and applicate widely in the world wide include the IMF financial robustness evaluation system, the macro-prudential indicators (MPIs) of Euro Central Bank (ECB) and other commonly used macro financial monitoring systems.

\subsection{The IMF financial robustness evaluation system}

The IMF financial robustness evaluation system is proposed by the International Monetary Fund and the World Bank, provides a standard of reference for the construction of the world financial stability assessment system. In accordance with the standard of the unified financial institutions rating system, the IMF evaluation system explores the robustness level of financial institutions through five aspects include the capital adequacy, asset quality, earnings and profitability, liquidity, and foreign exchange risk. The core indicators usually can be applied in most countries.

\subsection{The macro-prudential indicators (MPIs)}

The macro-prudential indicators (MPIs) of Euro Central Bank is based on the IMF financial robustness evaluation system. In view of the EU member states, based on the banking merger data 174 indicators are constructed. This set of indicators can be classified into three parts: bank internal indicators, indicators of crisis conduction factors and macroeconomic indicators which have impact on the banking system.

\subsection{The financial macro monitoring indicators}

The financial macro monitoring indicators can quantitatively reflect the health and stability of a country's financial system, plays an important role in the process of risk identification and prediction. It can be divided into the macroeconomic indicators and integrated micro financial indicators. The macroeconomic indicators used to measure the correlation between the financial system robustness and the level of macro-economic development. The integrated micro financial indicators used as a measure of the running status of financial institutions.

\section{The measurements of financial stability}

The development of computer technology makes the measurement of financial stability develop from qualitative analysis to quantitative analysis and from the description of the general analysis to the accurate statistical analysis. The development of the measurements of financial stability plays a key role in the world monetary authorities prevention, risk identification and management of the financial system. The development of the measurements of financial stability is summarized in figure1. 


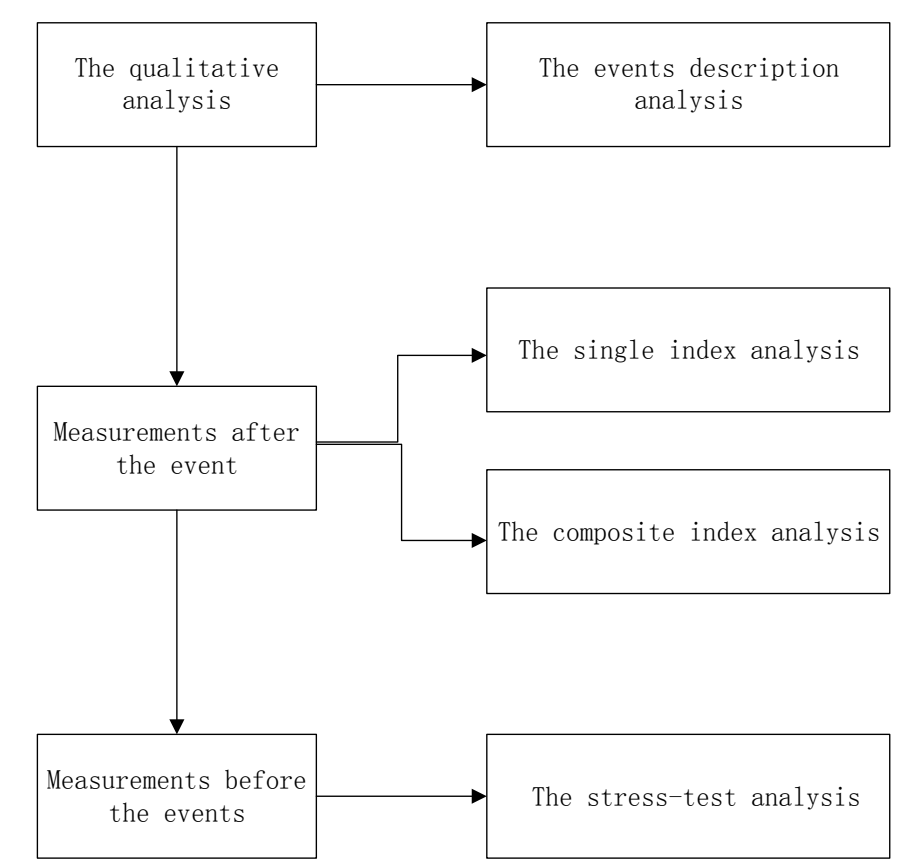

Figure 1 the development of the financial stability measurements

\subsection{The events description analysis}

The events description analysis usually used in the early state of the financial stability research which focus on the change of relevant economic variables before and after the financial crisis. It finds out the most significant change of economic variables through comparative analysis, and use it to reflect the financial fragility. However, as qualitative analysis the events description analysis has disadvantages. On one hand, the time point of the explosion of monetary crisis can't be specifically measured which would cause the mismatch between the crisis event and the index; The study of variable wave just stays on the qualitative description stage, it cannot be quantitatively depict the correlation between the economic variables and crisis[4].

\subsection{The single index analysis}

The single index analysis is a typical measurement after events. Single index analysis extracted core economic indicators which changed from an already happened financial crisis, then based on these changes in economic indicators status, evaluate the safety of the financial system at present stage. In this way, screening the most representative indicators to measure the change of financial stability becomes the key of this measurement. The core index screening methods mainly have two kinds: the threshold signal under the minimum signal noise ratio and the multivariate regression analysis method. The biggest improvement of the single index analysis is that it measures the internal factors and the change of the economic indicators which influence the stability of the financial system from a quantitative point of view. However, this method cannot integrate information responses by various economic indicators. And the multivariate regression analysis method is mostly adopted virtual variables to describe whether the financial crisis occurs, it ignores the situation which the financial system is on the critical state of crisis.

\subsection{The composite index analysis}

The composite index analysis is on the basis of single index analysis method, gives certain weight coefficient to the different economic indicators then get a comprehensive index to degrees the stability of the financial system[5]. It has two steps: firstly, screening the core indicators which can response the stability level of financial system. Then reasonably give weight coefficient for different indicators, and concluded the comprehensive index which could reflect the stability of the entire financial system through the weight value calculation of those indicators. Compared with single index analysis, the composite index analysis can synthetically reflect the stability change of different departments and different market, and it also can continuous measure the financial stability that the synthetic index in different numerical interval represents the different levels of financial stability. Moreover, once the financial crisis outbreak, its influence is not limited to the financial system but 
will spread to the real economy, the introduction of synthetic index analysis provides convenience for the macro econometric analysis.

\subsection{The stress-testing analysis}

The macro stress-testing analysis has become the most commonly used method the financial departments use to measure the stability level of financial system. It uses the simulation technology to simulate some exceptions credible macroeconomic shocks, and characterization of its impact on the financial system robustness. The most significant different the stress-testing analysis from the other three methods is that it is a measurement before the events which makes it becomes the most popular method to evaluate the stability of financial system. Right now, because the measure about liquidity of the market has not been unified, the market risk and credit risk can't be integrated and join the pressure test.

\section{Conclusion}

According to the analysis of the evaluation indicators of financial stability proposes by international financial organizations or institutions and financial regulatory agencies and the development of the measurements of financial stability, it can be summarized that the financial stability measuring methods has through three development stages, the qualitative analysis, measurements before and measurements after the events. The measurement of financial stability provides an important theoretical basis and practical experience for the economic growth promoting effect, the early warning of financial crisis and crisis management and policy making.

\section{References}

[1] Allen, W.A. and G. Wood, Defining and achieving financial stability. Journal of Financial Stability, 2005. 2(2): p. 152-172.

[2] Schinasi, G.J., Defining Financial Stability. Imf Working Papers, 2004. 04(4/187): p. págs. 37-55.

[3] Ferguson, R.W., Should Financial Stability be an Explicit Central Bank Objective. Monetary Stability Financial Stability \& the Business Cycle Five Views Bis Papers, 2003.

[4] Click, H.R. and A. Hutchinson, The Rising Agenda of Physician-Assisted Suicide: Explaining the Growth and Content of Morality Policy. Policy Studies Journal, 1999. 27(4): p. 750-65.

[5] End, J.W.V.D., Indicator and boundaries of financial stability. Dnb Working Papers, 2006(097). 